Respect pilot ...

Running head: Respect pilot

Paper submitted to Managing Leisure - An International Journal April 2009

\title{
Respect: Results of a pilot project designed to improve behaviour in English football
}

Celia Brackenridge ${ }^{1}$, Andy Pitchford ${ }^{2}$ and Marcia Wilson ${ }^{3}$

1 Brunel University

2 University of Gloucestershire

3 University of East London

\section{Address for correspondence:}

Professor Celia Brackenridge

Centre for Youth Sport and Athlete Welfare,

School of Sport and Education

Brunel University

Uxbridge

UB8 3PH

UK

07815881329 (mobile)

celia.brackenridge@brunel.ac.uk

Acknowledgements: The authors wish to express thanks to colleagues who assisted with data collection: Jamie Cockayne, Christina Gipson, Sadie Hollins, Rachel Kent, lain Lindsay, Katie Maddocks, Julie York (Brunel University), Mark Elliot, Dai Carpenter, Christopher Peach, Jonathan Carl Morley, Luke Court (University of Gloucestershire), Liz Kinder (independent consultant, BHT Associates) and Brenda Read (independent consultant, PESAS).

Words: 7043 
Respect pilot ...

\section{ABSTRACT}

The research on which this article reports arose from recognition by The English Football Association (FA) that poor behaviour in affiliated football was having widespread and deleterious effects on the game, at every level, including a loss of about 7,000 referees each year. In order to address these concerns, The FA implemented a programme of pro-social behaviour change, branded 'Respect', and commissioned research into a 3 month pilot project in a small number of County FAs during the spring of 2008. In designing the evaluation for the Respect Pilot the researchers attempted to adhere to best practice in programme evaluation by addressing both the process and outcomes of the intended change programme (Coalter, 2007; Pawson, 2006; Weiss, 1998) and by working with a logic model that could be adapted over time (Aspen Institute, 2003; Schmitz and Parsons, 2007). The four main stakeholder groups identified to take part in the Pilot were players, coaches, referees and spectators/parents, for three age groups Under 10, Under 16 and Open Age. Three different interventions were tested at the matches: designated spectator areas, codes of conduct with sanctions and only the captain being allowed to talk to the referee. Interviews were conducted with the four stakeholder groups at three games in each age group. In addition, week-by-week behaviour assessments from 583 trial games were entered online by over 1,000 people. Overall, both enjoyment and behaviour scores among the Active (experimental) teams were perceived to be significantly better than that among the matched Control teams (with no interventions). The experimental teams also ranked all three interventions highly over the ten weeks, with the designated spectator areas rated best, followed by the signing of codes of practice second and only captains talking to referees third. The results are discussed in relation to the future plans for the Respect campaign and the efficacy of the original logic model.

Key words: Football, behaviour change, Respect 
Respect pilot ...

The research on which this article reports arose from recognition by The English Football Association (FA) that poor behaviour in affiliated football was having widespread and deleterious effects on the game, at every level (The FA, 2008). In particular, a measured loss of about 7,000 referees year on year - much of it because of abuse from players and spectators - was predicted to present a serious threat to the future of competitive football. The FA was and is not alone in its struggle to regulate poor behaviour from its participants, whether on or off the field of play. The Labour Government introduced its own Respect agenda to tackle anti-social behaviour and to try to create a modern culture of respect that permeated all parts of civil society (Home Office, http://www.respect.gov.uk/article.aspx?id=9054 29 Jan 2008). In other parts of the sporting world similar schemes and initiatives have been developed, notably in Australia (http://www.playbytherules.net.au ) and Canada (http://www.respectinsport.com ) : and within football itself, both FIFA (1993) and UEFA (UEFA, 2008; Chaplin, 2008) have pursued similar agendas linked to fair play and respect. Other sports in the UK have, likewise, adopted such campaigns often repeating 'respect' as a brand name (Rugby Football League, 2008).

Conformity with behaviour standards arises from a mix of intrinsic and extrinsic motivation, of calculation and emotion, of 'carrot and stick'. The FA was aware that most of its participants are motivated by a love for the game and that either over-harsh or too lax a disciplinary regime might drive people away from football. Getting the balance right is a very difficult challenge for any governing body of sport, not least the one charged with managing England's national game. However, for English football to maintain its health, and for its stakeholders - especially referees and young players - to take satisfaction and enjoyment from their involvement, clearly something had to change.

This article reports on the results of the Respect Pilot project that took place over three months during the spring of 2008. More than 10,000 individuals and seven 
volunteer County FAs participated in some way, testing a number of game interventions and providing quantitative and/or qualitative feedback. The results of the Pilot, discussed below, were considered by the governing body to be so successful that the scheme was extended throughout the FA's Professional and National Games in the 2008-09 season.

\section{Seeking respect}

In preparing its National Game Strategy 2008-2012 - Your Game, Your Say, Our Goal The FA undertook a public consultation with more than 20,000 stakeholders in the game, including adults, young people, and partnership organizations (The FA, 2008). According to this consultation, football at that time was beset by poor/abusive behaviour, by players, spectators (including parents/carers) and coaches, especially in the youth and children's game. Poor behaviour occurred among amateur and professional players of all ages, both amongst themselves and towards the referee. The game was haemorrhaging referees because of this problem. Referees at all levels thus required protection from abusive people on the sidelines and the field of play. So-called 'pushy parents' on the sideline at children's matches were deemed to be especially culpable.

These problems are not unique to English football: in 2007, for example, a strike by eight year old players in Italy was the consequence of spectators' fights, pitch invasions and insults to referees (Kington, 2007). But the scale of the problem in England alarmed many people inside and outside the affiliated game. Indeed, dozens of matches across the country had to be abandoned in 2008 because of bad behaviour (SKY News, 2008; The Independent, 2008).

In order to address these concerns, The FA decided to implement a programme of behaviour change. The programme was branded 'Respect' and was intended to permeate the entire FA community. It was championed by the-then Chief Executive Officer, Brian Barwick, and was intended to raise awareness and standards in the 
Respect pilot ...

affiliated game and to compliment existing standards promoted through The FA's Equality Policy, Safeguarding Policy and Laws of the Game (http://www. TheFA.com ).

The FA proposed the Respect Pilot based on a set of beliefs or assumptions about behaviour change, viz:

- that bad behaviour needed to change

- that bad behaviour could change

- $\quad$ that good behaviour could be identified

- $\quad$ that change can be sustainable

- that improved behaviour would help the longer term health and image of the game, including stemming referee and player attrition

... and a set of values that underpin 'good' behaviour in the game, viz:

- $\quad$ that everyone has a right to enjoyment free of abuse and maltreatment

- $\quad$ that maintaining good behaviour and safeguarding the environment for children and all participants is a personal and collective responsibility

The FA was not the first sport organisation to engage in such work. JustPlay in Canada, Raakman, 2006; http://www.wejustplay.com ) and Play by the Rules in Australia (http://www.playbytherules.net.au ) are just two examples of many alternative behaviour change programmes overseas that arose from ethical concerns in youth sport. In the UK, a study of junior football club touchline behaviour was carried out by the Northumberland Association of Clubs for Young People (NABC) via an online survey from $15^{\text {th }}$ Jan-29 $9^{\text {th }}$ Feb 2008. The survey addressed Under 17 s to Under 11 s. In the report of this study, the NABC wrote:

We should ensure children have the right to enjoy their football in a safe environment that encourages development without being subjected to 
Respect pilot ...

unwarranted verbal or physical abuse / interference from team-mates, parents, coaches, spectators or anyone else for that matter. (NABC, 2008, p. 2)

Headline findings from the survey were that:

- $85 \%$ of respondents had witnessed verbal abuse of an official

- $27.5 \%$ admitted to being guilty of some sort of abuse

- $71 \%$ thought that parents were the main protagonists

- $57 \%$ thought that Clubs should be leading the way in tackling abusive behaviour

- $69 \%$ had a parents' charter/code of conduct in their club

- $71 \%$ claimed to know who to go to if they wished to report a problem

A range of proposals was put forward to change things, including:

- Neutral referees

- Behaviour monitors/ officials at each game

- Naming and shaming

- Banning parents

- Five yard exclusion zone

- Independent monitoring of known 'trouble makers'

- Severe penalties

- Self-regulation

In the same year, the magazine Total Youth Football also conducted its own campaign - called Keep it Shut! - and published a survey of abuse in the youth game, to which 574 people replied (Total Youth Football 2008, pp.24-27). The magazine reported that:

- $83 \%$ had witnessed unacceptable verbal abuse or interference from parents or spectators of a youth football match in the previous 12 months 
Respect pilot ...

- $82 \%$ had witnessed such abuse aimed at match officials, from the touchlines and/or from players themselves

- $21 \%$ had witnessed match-related physical violence involving parents or spectators or on the touchline

- $45 \%$ said there was no problem with referee abuse at their club

- 30 respondents $(5 \%)$ had witnessed actual physical abuse of children at games

- $61 \%$ thought that national football associations should be at the forefront of dealing with abuse issues in youth football

Respect was clearly, then, an idea whose time had come. But, as indicated above, Respect is not just a football issue. Pro-social and anti-social behaviour, and especially parental behaviour, is a focus of attention for both policy makers and practitioners right across the social spectrum in youth sport. It has also been the subject of many research studies which repeatedly suggest that the social climate of the game and the socialisation potential of coaches, parents and role models are the main influences on good or bad behaviour in youth sports (Holt et al., 2007; Rutten et al., 2007). Fair play and personal and social responsibility are also much-researched themes in the sport science literature (for example, Bredemeier, 1987; Bredemeier et al., 1994; Cecchini et al., 2007; Shields et al., 2007; Sage and Kavussanu, 2008).

\section{Measuring behaviour change}

There is a sizeable and rapidly growing literature about programme evaluation. Current thinking encourages researchers to address the process and outcomes of a change programme and not to focus solely on outcomes (Coalter, 2007; Pawson, 2006; Weiss, 1998). In setting up the evaluation for the Respect Pilot the researchers attempted to adhere to this approach and also to acknowledge guidance from the 
Respect pilot ...

Institute for Public Policy Research (http://www.ippr.org.uk/events/?id=2194 , 2006)

which highlighted several key factors that influence the success or otherwise of behaviour change programmes and their evaluations. These are:

- Education of the media about research and evaluation of the programme

- Political timing, which may be more significant than data in the way programmes are announced and promoted

- Clear and simple delivery of evaluation results by researchers to clients

- Threshold spending on the programme to avoid quick results that equally quickly dissipate

- The need "to motivate, empower and give people skills" since attitude changes do not guarantee behaviour change

- Cultural climate, which needs to change alongside attitudes in order to reinforce the logic of the required change

- Measurement of all parts of an intervention and all stakeholders who might be involved

- The context-dependent status of any behaviour change: "Evidence based policy may work at one time but then fail to work at a later date"

- The need for researchers and clients to establish an ongoing and fluid discourse about a behaviour change programme "researchers should be able to come forward, offer their expert opinion and suggest new objects of analysis".

[Insert Fig. 1 about here]

In line with theory of change approaches proposed by the Aspen Institute (2003; Theory of Change, 2007), a logic model was drawn up for the research (Fig. 1). Logic models date back to the 1970s (Wholey, 1979; Kellog Foundation, 2001; Aspen Institute, 2003; Schmitz and Parsons, 2007) and have subsequently been used in public, private and 
Respect pilot ...

non-for-profit sectors as a tool of programme planning and evaluation. They have especially been applied in quality management evaluation e.g. Total Quality Management. In the not-for-profit sector, which we could argue includes organisations such as The FA, logic models have been used as part of the United Way (2009, http://www.liveunited.org/outcomes/? ), a method of outcomes measurement.

\section{THE STUDY}

In order to test their plans for Respect, The FA commissioned research into a pilot project in a small number of County FAs. The researchers interpreted the purpose of The FA Respect project overall as achieving sustainable, positive behaviour change among three of the key stakeholder groups (players, coaches and parents/spectators) and sustainable positive game experiences for the fourth group of stakeholders - referees associated with these games. The two main desired outcomes for The FA were: first, to retain referees and stem attrition caused by their negative experiences; and, secondly, to improve the standard of behaviour of spectators, including parents, by addressing the bullying and verbal abuse experienced by children at youth and children's games. The research questions addressed were:

RQ1: What do the four stakeholder groups think about the need for a behaviour change programme before and at the end of the Pilot?

RQ2: How respectful do the stakeholder groups think that their own and other groups' behaviour is at each game?

RQ3: What are the experiences of the four stakeholder groups with regard to three different interventions being trialled?

\section{Sample}


Respect pilot ...

The four main stakeholder groups identified to take part in the Pilot were players, coaches, referees and spectators/parents, for three age groups - Under 10 (U10), Under 16 (U16) and Open Age (OA). Four treatment groups were identified (see Table 1). Target numbers of respondents for the different measures are identified at the top of each column in Table 1. The minimum number of responses for any sensible statis tical analysis was set at $100+$ within each cell.

[Insert Table 1 about here]

Assuming that an average of four home spectators, one referee, one coach and four players at each game were interviewed this meant that $10 \times 27=270$ people would potentially be involved in the interview stage of the pilot (see Table 2) and potentially several thousand more through the online system.

[Insert Table 2 about here]

\section{Interventions}

Three different interventions were trialled at the matches over a ten week period from late January 2008. These were:

1) Designated spectator areas: these were marked off at 2 metres from the side of the pitch using tapes and short posts. Guidance was given to spectators as to the purpose of the scheme and the sanctions for not complying with it. Spectators were kept at separate sides of the pitch with only the coach/team manager and assistant manager allowed to the opposite side.

2) Codes of conduct with sanctions: everyone connected to the club was required to sign up to adhere to a code of conduct, which also indicated sanctions for breaches. 
Respect pilot ...

Players in youth football had their parents/carers sign the code in addition to signing one themselves. Players and coaches in OA football also signed in order to participate in the Respect Pilot.

3) Only the captain talks to referee: Teams were informed they must have a captain on the pitch at all times and s/he would be the only person allowed to talk to the referee. Any other player complaining at or abusing the referee would be warned and dealt with under the Laws of the Game (and issued with a yellow/red card if necessary).

\section{Instruments}

[Insert Figure 2 About here]

The methods used to address the research questions were as follows:

a) A benchmarking exercise to assess the attitudes of key stakeholder groups to the Respect programme (quantitative) (RQ1 and RQ2). An Activation States model was originally designed as a heuristic device to assess the feelings, thoughts, actions and discourses of different groups towards child protection in football (Brackenridge et al., 2005). In that project it was used with qualitative data from semi-structured interviews. For the Respect Pilot, the model it was reframed as a quantitative tool using a number of Likert items to capture two sub-scales within the spectrum of Activation States - 'opposed' and 'supportive' (see Fig. 2). This, together with an adapted version for children, was validated specifically for the Respect Pilot. However, because insufficient data were forthcoming, the results from the benchmarking exercise are not reported here.

b) Longitudinal data collection of week-by-week behaviour assessments by referees (quantitative), using specially designed surveys on The FA's Full Time website (RQ2). This was an extension of the tool used for club officials to enter match 
Respect pilot ...

scores. Full Time comprises a national database of games in affiliated leagues. For the Respect Pilot, the it offered users simple reporting grids against which stakeholders could input scores for different aspects of behaviour after each of their games. Comparison of qualitative and quantitative datasets was enabled by respondents using their unique identifier known as a FAN (FA number).

c) Intermittent longitudinal data collection about stakeholders' experiences of the range of behaviour change interventions (qualitative) through semi-structured faceto-face and telephone interviews (RQ3). A sample of key stakeholders from each of the four types (referees, spectators, players and coaches) was invited to give interviews after three home games (c. weeks 1,5 and 10) to provide richer explanations of their experiences of the pilot project and, in particular, to comment on each of the interventions being trialled.

Respect Information Packs were prepared by The FA, tailored for the County FAs, Clubs and Referees and briefings given to County FA personnel several weeks prior to the start of the Pilot.

\section{Data handling and security}

Other than the teams, coaches and referees in Treatment Group C, no teams or individuals were identified by name to the researchers. In order to ensure this, a oneway filter system was operated whereby:

$>$ The FA selected those in all Treatment Groups

The FA notified the researchers only of the contacts for teams in Group C

$>$ Data from Groups A, B and D were fed back to the researchers as generic, aggregated datasets/reports (quantitative) and as chunks of anonymised text reports from the e.mail/text box option (qualitative) 
Respect pilot ...

$>$ The researchers anonymised all interview transcripts for analysis purposes and stored the consents forms and transcripts separately, using a coding system

$>$ Raw (original) data will be destroyed on completion of the project

In this way the research team was not involved in selecting or knowing the source of the data from Groups A, B or D and The FA was not privy to the identity/source of the results. This system was used to secure anonymity and confidentiality.

\section{Ethics}

Approval for the research was secured from the appropriate ethics committee at Brunel University prior to the collection of any data. Researchers were appointed in three sites (see Table 3), based on their research skills, knowledge of football and previous experience in similar research projects. All were suitably Criminal Records Bureau checked prior to the start of field work. Research staff were inducted into the project by face-to-face meetings, e.mail or telephone and issued with a comprehensive specification for the project in the form of a Research Team Guidelines Booklet (also copied to The FA) that set out the rationale, protocols and instruments for the research together with confidentiality agreements, sample consent and incident forms, media and ethics guidance. Fieldworkers were advised to attend an FA or Sports Coach UK workshop on safeguarding/good practice when working with children.

\section{RESULTS AND DISCUSSION}

Weekly on-line surveys

[Insert Figures 3 and 4 about here]

Over 1,000 people completed online surveys on a weekly basis throughout the ten-week Respect Pilot. Participants reported on a total of 583 matches. Overall, enjoyment among the Active (experimental) teams was perceived to be significantly 
Respect pilot ...

better than that among the Control teams (Fig. 3). The variation in the pattern for the Control groups across the ten week Pilot can be attributed to the lower numbers of survey respondents from these groups. Similarly, the overall behaviour scores were consistently better among the Active groups than the Controls, with only a little variation (Fig. 4). With regard to the three interventions, the Active groups ranked all of them consistently highly over the ten weeks, with the designated spectator areas rated best, followed by the signing of codes of practice second and only captains talking to referees third (Fig. 5).

[Insert Table 3 about here]

It is possible to see a finer grain response to the three interventions by looking at the interview data. Obviously one cannot conduct statistical testing as such on qualitative data but answers about each intervention were scored as 'positive', 'neutral' or 'negative' (with inter-rater reliability of $80 \%+$ ). Table 3 shows the aggregate scores by age group and role respectively. In terms of ratios, the U10s were about 4:1

positive:neutral, the U16s 5:1 and the OA just over 2:1 with 7 negatives. The overall picture was thus very positive, especially in the junior game. The results by role show slightly more equivocation about the interventions among the coaches and players (just under 3:1 positive:neutral in each group) and more enthusiasm among the referees and spectators (at 5:1 in each).

General views were characterised by the following excerpts.

Positive:

l'd do it straight away for everybody. Do not even bother with these trials just get it out there; it is fine. (Referee, OA) 
Respect pilot ...

Yes its all good as long as it works out fine, and everyone sticks to the rules then it shouldn't be a problem. (Player, OA)

Neutral:

... the younger people. They just mimic what's happened. Not only are they influenced by the good, they are unfortunately influenced by the bad and this is the problem ... In my opinion it should be vice versa from the top down. (Referee, $\mathrm{OA})$

Well I don't think the FA can do much really, it's up to the people, if they behaved in the proper manner, that they should do, then there shouldn't be any problems. (Spectator, OA)

Negative:

Well you can't mess about with the game too much. It has been going hundreds of years so ... (Spectator, OA)

Your captain, vice-captain might play left back, right back and they've still got to run. They want to play football and keep the flowing game. That's what they play for at free kicks, and if you've just got the captain and vice-captain talking to the referee it's going to stop the tempo of the game. In cold weather you're going to have people standing around getting cold waiting for the players to talk, then get back into position and then get all started and set up again. It's too much time. (Player, OA)

In summary, from the 73 interviews conducted, the Under 10 s were positive:neutral about the interventions in a ratio of about 4:1, the Under $16 \mathrm{~s} 5: 1$ and the Open Age just over 2:1. The interview responses to the interventions, when analysed by 
Respect pilot ...

role, showed slightly more equivocation among the coaches and players (just under 3:1 positive:neutral in each group) and more enthusiasm among the referees and spectators (at 5:1 in each). The overall picture was thus very positive, especially in the junior game.

\section{The interventions}

a) Designated spectator areas: Of the three interventions, this was the most popular, scoring 4.25 or above out of 5 among all stakeholder groups and age groups (Figs 5 and 6). Again, the qualitative data reinforce the survey results, showing that all four stakeholder groups strongly welcomed the use of designated areas (Table 4). An age group split apparent here, with the two junior groups being positive:neutral in a ratio of 6:1, and the Open Age group half this at just under 3:1.

[Insert Figures 5 and 6 about here]

[Insert Table 4 about here]

Many very positive comments were made about this intervention, including the following: Every club, every age group, should have those things, I think it is a great idea. (Coach, U16)

...it's like a psychological barrier which is quite good. (Player, U16)

It's good because when taking corners and throw-ins you have enough room to take it properly. (Player, U10)

... it's a sensible precaution that allows people to know where they should be, it definitely provides a distinct zone of control for the pitch. (Referee, OA) 
Respect pilot ...

Some were not convinced, either about the need for the measure or about the efficacy of the equipment that had been provided:

... if they are going to provide us with a rope then give us the tools for the job, but the idea about the rope and standing behind the rope is correct. That's good. (Coach, OA)

I don't think you need to rope the pitches off at this type of club.

$$
\text { (Spectator, OA) }
$$

And others objected, not in principle but because they had their own, better materials:

... the rope is not up to it. We've been given a rope but we haven't used it. Today we got out own rope, which is far more suitable. (Coach, OA)

... the ones the FA gave, are blowing away, yeah, they are having problems keeping them in place. (Referee, OA)

In conclusion, the designated areas were well received, being regarded as a safety improvement (no running into people, dogs, chairs etc.) and an improvement in sight lines for all. Reasons given for objecting to them were mainly that the construction was flimsy or that they required too much time and effort to put up and take down again.

[Insert Table 5 and Figure 7 about here]

2) Codes of conduct with sanctions: This was the second most popular intervention with all stakeholder groups giving it a score of 3.75 out of 5 or above (Fig 7). The interview data slightly contradict the online survey responses. Table 5 shows that the 
Respect pilot ...

coaches and players who were interviewed were more cautious than the referees and spectators about the signing of codes of conduct, with more of them expressing neutrality than the referees and spectators who appear almost wholly positive about the codes.

Regarding age-related responses, the Open Age group was also less keen on the codes of conduct than the other groups, with a ratio of about $2: 1$ positive:neutral, as against 4:1 in the two lower age groups. The pattern overall, however, was very positive. Positive comments about codes of conduct included:

... it's good, because when you sign it, the manager will say sign this and this is the code of conduct. What it will do is makes people a bit aware of it brings to the forefront the idea that you should behave yourself on the pitch. (Coach, U16)

It is good because we have rules to follow and if we break them we may not play. It is very important. (Player, U10)

I think it's a good idea, the youngsters are used to it now because a lot if the colts team have called it in and that's not just for players, it's for coaches and for parents as well. (Spectator, OA)

There seems to be a consensus that they are going to try and make it work. (Referee, OA)

Some more sceptical comments included: 
Respect pilot ...

I can understand why they have them but they have no effect. Everyone will commit and sign them but the next day they will break the rules. (Spectator, $U$ 10)

... it smacks of a Labour government ... signing up for everything ... I don't believe in that. (Spectator, OA)

In conclusion, the idea of signing up to codes of conduct was well-received but thought to require some reinforcement.

[Insert Table 6 about here]

[Insert Figure 8 and 9 about here]

3) Only captains speaking to the referee: This emerged as the least well-supported of the three interventions, with some variability among the stakeholder groups. In the weekly surveys, the referees appeared to be the most cautious group about this intervention (Fig. 8). However, the interview data revealed a somewhat different picture (Table 6), with the players indicating the most neutral and negative responses.

There were clear age group differences in the responses to this intervention (Fig 9), with higher support among the lower age groups. The interviews confirmed this: the OA and U10 groups combined expressed positive:neutral:negative ratios of about 4:2:1. Those in favour of this intervention were very keen indeed and thought the idea long overdue:

It is quite good because you cannot have the whole team shouting at the referee. It also wastes a lot of time doing that. It helps to put less pressure on the referee. (Player, U10) 
Respect pilot ...

... it saves everyone else having a go at people for no reason. (Player, U16)

I think that's a great idea. It will take time for the players to adapt. (Coach, OA)

I think that is eminently sensible. I would have liked to have seen them done before and I would like to see them at all levels of the game. (Referee, OA)

... probably be quite good if just the captain does it on his own, and I think its quite a good idea really. (Spectator, OA)

Other were neutral about the idea but gave reasons for their views:

... when you get to this level you need to have two official linesmen as well as a referee because when you have just got the one that, at the end of the day, is a father of one of the lads it can cause upset. (Coach, U10)

... why have they brought it in at this level and not started at the Premiership? (Spectator, OA)

As a senior county ref I want players to talk to me. With the lads starting out level $7 s$ and $6 s$ this is great. (Referee, OA)

... in rugby with different rules if someone else speaks you get a ten yard penalty that's not going to happen in football. (Player, OA) 
Respect pilot ...

Opposition to the interventions was voiced as follows:

They said only captains can talk. And he said (referee) no I don't want that. I want any player to come over to me and talk to me. (Spectator, OA)

If you stop players from talking to me as a senior ref official, you will take the passion out of the game. I want players to talk to me as I am experienced enough and old enough to man manage ... (Referee, OA)

Yeah I mean you're putting pressure on a nine year old kid to carry a whole team and to me that's too much. They have to look after their own game - that's more important! (Spectator, U10)

In conclusion, this intervention was welcomed with only a few reservations, mainly about whether Under 10 captains could cope with the responsibility or whether the stipulation restricted reasonable talk by other players.

\section{Limitations}

Although the overall picture from the research looks very positive, there are underlying reasons why caution should be exercised in the interpretation of the results, especially by The FA. First, insufficient responses were received for any meaningful statistical analysis of the benchmarking exercise at the start and end of the ten week study so this element is not reported here. Without strong benchmarking data at the start of a programme intervention, and a clear direction of travel towards specified and measurable outcomes, it is difficult to know whether any changes that are discerned can be attributed to the intervention or to some other causes. Such 'other causes' in the 
Respect pilot ...

Respect Pilot might include prior knowledge of Respect because of frequent leaks to the media prior to the launch of the Pilot (e.g. Donegan, 2007 and Lansley, 2007), and to a range of contextual issues and confounding variables such as class, race etc. (identified in Fig. 1). Indeed, the original logic model requires adaptation to account more clearly for both confounding variables and unexpected outcomes in the trial of Respect.

There was also a considerable drop off in the number of people completing the on-line surveys toward the end of the Pilot, especially among the Control groups. The purposive selection of experimental teams - whose leagues volunteered and selected them for the Pilot - may have produced a positive skew or Hawthorne Effect (Roethlisberger and Dickson, 1939) in the results. There could also have been a peer group effect whereby improved behaviour was elicited through 'norming', the tendency of people in groups to conform with group behaviour (Tuckman, 1965). Finally, there was an absence of data from women and girls. No female teams appeared in the experimental sample and the number of female survey respondents was negligible meaning that no gender analysis could be conducted.

\section{Conclusions}

In many ways The FA's highest hopes for the Respect pilot project were realised. All four stakeholders groups reported positively about the three game interventions, with referees and spectators very willing to adopt them, and with players and coaches willing but more equivocal. Although this appears to bode well for the future of Respect the dissenting voices in the data also need to be heard. Several of these offered interesting and constructive suggestions which The FA has committed to explore further. It is far too early to judge whether the longer term aims of The FA for Respect will be met but the adoption of Respect as an embedded 'programme', rather than merely a 'campaign', across both the Professional and National Game from the 2008-09 season 
Respect pilot ...

(http://www.thefa.com/Leagues/Respect.aspx ) will facilitate further and more extensive evaluation research.

\section{References}

Aspen Institute (2003) 'Making sense: Reviewing program design with theory of change', ActKnowledge and the Aspen Institute Roundtable on Comprehensive Community Initiatives. http://www.theoryofchange.org/pdf/making sense.pdf Retrieved 4 Jan 2008.

Brackenridge, C.H., Pawlaczek, Z., Bringer, J.D., Cockburn, C., Nutt, G., Pitchford, A. and Russell, K. (2005) 'Measuring the impact of child protection through Activation States', Sport, Education and Society, 10(2), 239-256.

Bredemeier, B.J.L. (1994) 'Children's moral reasoning and their assertive, aggressive and submissive tendencies in sport and daily life', Journal of Sport and Exercise Psychology, 16, 1-14.

Bredemeier, B.J.L., Weiss, M.R., Shields, D.L. and Cooper, B.A.B. (1987) 'the relationship between children's legitimacy judgements and their moral reasoning, aggression tendencies and sport involvement', Sociology of Sport Journal, 4, 48-60.

Cecchini, J.A., Montero, J., Alonson, A., Izquierdo, M. and Contreras, O. (2007) ‘Effects of personal and social responsibility on fair play in sports and self-control in school-aged youths', European Journal of Sport Science, 7(4), 203-211. 
Respect pilot ...

Chaplin, M. (2008) 'UEFA unveils 'Respect' initiative', $12^{\text {th }}$ March

http://www.euro2008.uefa.com/news/kind=1/newsid=671250.html Retrieved 29 Jan 2009.

Coalter, F. (2007) A Wider Role for Sport: Who's keeping the score? London, Routledge.

Donegan, L. (2007) 'It's crazy to suggest that respect for referees must start at bottom', The Guardian, Sport, 4 Oct, p. 8.

FIFA Fair Play Code (1993)

http://www.fifa.com/aboutfifa/worldwideprograms/footballforhope/fairplay/code.html Retrieved 18 Apr 2009.

Holt, N.L., Tamminen, K.A., Black, D.E., Sehn, Z.L. and Wall, M.P. (2008) ‘Parental involvement in competitive youth sport settings' Psychology of Sport and Exercise, 9, 663-685.

Home Office http://www.respect.gov.uk/article.aspx?id=9054 Retrieved 29 Jan 2008.

Institute for Public Policy Research (2006) 'Evaluating behaviour change: Behaviour change and personal responsibility', http://www.ippr.org.uk/events/?id=2194 Retrieved 29 Jan 2008.

JustPlay (Canada) http://www.wejustplay.com Retrieved 21 Apr 2009. 
Respect pilot ...

Kellog Foundation (2001) Logic Model Development Guide: Logic models to bring together planning, evaluation and action. Battle Creek, MI: W K Kellog Foundation.

Kington, T. (2007) 'Junior football strike to keep parents in line', The Guardian, 17 Dec, p. 4.

Lansley, P. (2007) 'FA trial could lead to teams losing points for bad touchline behaviour', The Times, 28 Nov, p.82.

Northumbrian Association of Clubs for Young People. (2008) The NABC on-line Survey: Touchline behaviour, 15 Jan 2008-29 Feb 2008. Benwell, Newcastle: NABC.

Pawson, R. (2006) Evidence-based Policy: A realist perspective, London, Sage.

Play by the Rules, Australia http://www.playbytherules.net.au/ Retrieved 18 Apr 2009

Raakman, E. (2006) 'JustPlay: A revolutionary approach to youth sport administration and sportsmanship', Journal of PE Recreation and Dance, 77(6), 20-24.

Respectinsport http://www.respectinsport.com http://www.respectinsport.com/home.html Retrieved 18 Apr 2009.

Roethlisberger, F.J. and Dickson, W.J. (1939) Management and the Worker, Boston, MA, Harvard University Press. 
Respect pilot ...

Rugby Football League (2008) RESPECT Campaign presentation and leaflet, http://www.therfl.co.uk/community/page.php?areaid=30 Retrieved 29 Jan 2008.

Rutten, E.A., Dekovic, M., Stams, G.J. J.M., Schuengel, C., Hoeksma, J.B. and Biesta, G.J.J. (2008) 'On- and off-field antisocial and prosocial behaviour in adolescent soccer players: A multilevel study', Journal of Adolescence, 31(3), 371-387.

Sage, L.D. and Kavussanu, M. (2008) 'Goal orientations, motivational climate, and prosocial and antisocial behaviour in youth football: Exploring their temporal stability and reciprocal relationships', Journal of Sports Sciences, 26(7), 732.

Schmitz, C.C. and Parsons, B.A. (undated) 'Everything you wanted to know about logic models but were afraid to ask', http://www.insites.org/documents/logmod.htm Retrieved 7 Jly 2007.

Shields, D.L., LaVoi, N.M., Bredemeier, B. L. and Power, F.C. (2007) 'Predictors of poor sportspersonship in youth sports: Personal attitudes and social influences', Journal of Sport and Exercise Psychology, 29, 747-762.

Sky News (2008) FA Red Card No-Swearing Trial. Monday $10^{\text {th }}$ Mar. http://uk.news.com/skynews/20080310/tuk-fa-red-card-no-swearing-trial-45db Retrieved 29 Jan 2008.

The Football Association http://www. TheFA.com Retrieved 29 Jan 2008. 
Respect pilot ...

The Football Association (2009) Welcome to Respect

http://www.thefa.com/Leagues/Respect.aspx Retrieved 21 Apr 2009.

The Football Association (2008) National Game Strategy 2008-2012 - Your Game, Your Say, Our Goal, London, FA.

The Independent (2008) 'Turf war: How Britain's playing fields became a battleground', 14 Jan, http://www.independent.co.uk/uk/this britain/article3334063.ece Retrieved 29 Jan 2008.

Theory of Change (2007) 'Overview', http://www.theoryofchange.org/html/overview.html Retrieved 29 Jan 2008.

Total Youth Football (2008) 'Keep It Shut! The results', Total Youth Football, Issue 5, March, 24-27.

Tuckman, B. (1965) 'Developmental sequence in small groups', Psychological Bulletin, 63 (6), 384-99.

UEFA (12 March 2008)

http://www.euro2008.uefa.com/news/kind=1/newsid=671250.html Retrieved 18 Apr 2009

United Way (2009) Outcome Measurement Resource Network.

http://www.liveunited.org/outcomes/? Retrieved 21 April 2009.

Weiss, C.H. (1998) Evaluation, $2^{\text {nd }}$ Ed. Upper Saddle River, NJ, Prentice Hall. 
Respect pilot ...

Wholey, J.S. (1979) Evaluation: Promise and performance, Washington, D.C, Urban Institute Press. 
Table $1 \quad$ Treatment groups

\begin{tabular}{|c|c|c|c|c|}
\hline $\begin{array}{l}\text { Methods and } \\
\text { interventions }\end{array}$ & $\begin{array}{c}\text { A } \\
\text { (True } \\
\text { control) } \\
\mathrm{n}=\text { min of } 100 \\
\text { refs from each } \\
\text { age gp }=300+ \\
\text { refs }\end{array}$ & $\begin{array}{c}\text { B } \\
\text { (False } \\
\text { control) } \\
\mathrm{n}=\text { min of } 12 \\
\text { teams from each } \\
\text { age gp }=36+ \\
\text { teams }\end{array}$ & $\begin{array}{c}\text { C } \\
\text { (True } \\
\text { experimental) } \\
9 \text { teams only, } 3 \\
\text { from each age gp }\end{array}$ & $\begin{array}{c}\text { D } \\
\text { “Active 2" } \\
\mathrm{n}=\text { min of } 100 \\
\text { teams from each } \\
\text { age gp }=300+ \\
\text { teams }\end{array}$ \\
\hline $\begin{array}{l}\text { Benchmarking of all } \\
\text { stakeholders at start/end } \\
\text { of trial }\end{array}$ & & $\sqrt{ }$ & $\sqrt{ }$ & $\sqrt{ }$ \\
\hline $\begin{array}{l}\text { All three interventions } \\
\text { applied throughout }\end{array}$ & & & J & $\bar{J}$ \\
\hline $\begin{array}{l}\text { Weekly match reports on } \\
\text { behaviour via Respect } \\
\text { website }\end{array}$ & $\checkmark$ Refs ONLY & $\begin{array}{l}\sqrt{ } \text { Refs and } \\
\text { U10s }\end{array}$ & $\begin{array}{l}\text { Refs, coaches } \\
\text { and U10s }\end{array}$ & $\begin{array}{c}J \text { Refs, } \\
\text { coaches and } \\
\text { U10s }\end{array}$ \\
\hline $\begin{array}{l}\text { Intermittent semi } \\
\text { structured interviews } \\
\text { with coaches, refs, } \\
\text { spectators and players }\end{array}$ & & & $\bar{J}$ & \\
\hline $\begin{array}{l}\text { End of Pilot on-line } \\
\text { reports via Respect web } \\
\text { page text box }\end{array}$ & & & $\sqrt{ }$ & $\sqrt{ }$ \\
\hline
\end{tabular}

Key:

Group $A=$ true control (NB Barring referees, these were not told about the project)

Group $B=$ false control (these had been notified about the experiment by The FA so could not be used as a true control)

Group $C=$ true experimental

Group $D=$ supplementary experimental (i.e. all those volunteers who had been recruited by The FA prior to the engagement of the researchers but who could not be accommodated in the true experimental group) 
Table 2 Interview numbers for Treatment Group C

\begin{tabular}{|c|c|c|c|c|c|c|c|}
\hline \multirow{2}{*}{\multicolumn{3}{|c|}{$\begin{array}{l}\text { AGE GROUP, TEAMS AND } \\
\text { MATCHES }\end{array}$}} & \multicolumn{5}{|c|}{ NUMBER OF INTERVIEWS } \\
\hline & & & \multirow{2}{*}{$\begin{array}{c}\text { Referee } \\
\text { 1-to-1 }\end{array}$} & \multirow{2}{*}{$\begin{array}{c}\text { Home } \\
\text { players } \\
\text { group } \\
(n=6-8)\end{array}$} & \multirow{2}{*}{$\begin{array}{c}\text { Home } \\
\text { spectators } \\
\text { group } \\
(n=6-8)\end{array}$} & \multirow{2}{*}{$\begin{array}{l}\text { Home } \\
\text { coach } \\
1 \text {-to-1 }\end{array}$} & \multirow{2}{*}{ Total } \\
\hline $\begin{array}{c}\text { Age } \\
\text { group }\end{array}$ & Teams & $\begin{array}{l}\text { Matches } \\
\text { (Weeks 1, } \\
5 \text { and 10) }\end{array}$ & & & & & \\
\hline \multirow[t]{3}{*}{ U10 } & $A$ & 3 & 3 & 3 & 3 & 3 & 12 \\
\hline & $\mathrm{B}$ & 3 & 3 & 3 & 3 & 3 & 12 \\
\hline & $\mathrm{C}$ & 3 & 3 & 3 & 3 & 3 & 12 \\
\hline \multirow[t]{3}{*}{ U16 } & A & 3 & 3 & 3 & 3 & 3 & 12 \\
\hline & $\mathrm{B}$ & 3 & 3 & 3 & 3 & 3 & 12 \\
\hline & C & 3 & 3 & 3 & 3 & 3 & 12 \\
\hline \multirow[t]{3}{*}{$\mathrm{OA}$} & $\bar{A}$ & 3 & 3 & 3 & 3 & 3 & 12 \\
\hline & $\mathrm{B}$ & 3 & 3 & 3 & 3 & 3 & 12 \\
\hline & $\bar{C}$ & 3 & 3 & 3 & 3 & 3 & 12 \\
\hline \multicolumn{3}{|c|}{ Total one-to-one interviews } & 27 & & & 27 & 54 \\
\hline \multicolumn{3}{|c|}{ Total group interviews } & & 27 & 27 & & 54 \\
\hline & & & & TA & OTAL IT & VIEWS & 108 \\
\hline
\end{tabular}


Table 3 Aggregated interview responses to the three interventions, by age group and role

\begin{tabular}{|l|c|c|c|c|c|}
\hline Age group & Posi tive & Neutral & Negative & Not answ'd & Total \\
\hline Under 10 & 86 & 21 & 5 & 2 & 114 \\
\hline Under 16 & 15 & 3 & 3 & 3 & 24 \\
\hline Open Age & 49 & 21 & 7 & 4 & 81 \\
\hline Total & 150 & 45 & 15 & 9 & 219 \\
\hline \multicolumn{1}{|c|}{ Role } & Posi tive & Neutral & Negative & Not an sw'd & Total \\
\hline Coaches & 42 & 16 & 1 & 1 & 60 \\
\hline Players & 31 & 13 & 7 & 3 & 54 \\
\hline Refs & 38 & 8 & 3 & 2 & 51 \\
\hline Specs & 39 & 8 & 4 & 3 & 54 \\
\hline Total & 150 & 45 & 15 & 9 & 219 \\
\hline
\end{tabular}


Table 4 Interview responses to designated spectator areas, by age group and role

\begin{tabular}{|l|c|c|c|c|c|}
\hline Age group & Posi tive & Neutral & Negative & Not answ'd & Total \\
\hline Under 10 & 36 & 1 & 0 & 1 & 38 \\
\hline Under 16 & 6 & 1 & 1 & 0 & 8 \\
\hline Open Age & 19 & 7 & 0 & 1 & 27 \\
\hline Total & 61 & 9 & 1 & 2 & 73 \\
\hline \multicolumn{1}{|c|}{ Role } & Posi tive & Neutral & Negative & Not an sw'd & Total \\
\hline Coaches & 17 & 3 & 0 & 0 & 20 \\
\hline Players & 13 & 3 & 1 & 1 & 18 \\
\hline Refs & 15 & 2 & 0 & 0 & 17 \\
\hline Specs & 16 & 1 & 0 & 1 & 18 \\
\hline Total & 61 & 9 & 1 & 2 & 73 \\
\hline
\end{tabular}


Table 5 Interview responses to codes of conduct, by age group and role

\begin{tabular}{|l|c|c|c|c|c|}
\hline Age group & Posi tive & Neutral & Negative & Not answ'd & Total \\
\hline Under 10 & 29 & 8 & 0 & 1 & 38 \\
\hline Under 16 & 4 & 1 & 2 & 1 & 8 \\
\hline Open Age & 15 & 7 & 3 & 2 & 27 \\
\hline Total & 48 & 16 & 5 & 4 & 73 \\
\hline \multicolumn{1}{|c|}{ Role } & Posi tive & Neutral & Negative & Not an sw'd & Total \\
\hline Coaches & 11 & 8 & 0 & 1 & 20 \\
\hline Players & 11 & 5 & 1 & 1 & 18 \\
\hline Refs & 12 & 2 & 2 & 1 & 17 \\
\hline Specs & 14 & 1 & 2 & 1 & 18 \\
\hline Total & 48 & 16 & 5 & 4 & 73 \\
\hline
\end{tabular}


Table 6 Interview responses to only the captains speak, by age group and by role

\begin{tabular}{|l|c|c|c|c|c|}
\hline Age group & Posi tive & Neutral & Negative & Not answ'd & Total \\
\hline Under 10 & 21 & 12 & 5 & 0 & 38 \\
\hline Under 16 & 5 & 1 & 0 & 2 & 8 \\
\hline Open Age & 15 & 7 & 4 & 1 & 27 \\
\hline Total & 41 & 20 & 9 & 3 & 73 \\
\hline \multicolumn{1}{|c|}{ Role } & Posi tive & Neutral & Negative & Not an sw'd & Total \\
\hline Coaches & 14 & 5 & 1 & 0 & 20 \\
\hline Players & 7 & 5 & 5 & 1 & 18 \\
\hline Refs & 11 & 4 & 1 & 1 & 17 \\
\hline Specs & 9 & 6 & 2 & 1 & 18 \\
\hline Total & 41 & 20 & 9 & 3 & 73 \\
\hline
\end{tabular}


Figure 1 Logic model for the Respect Pilot

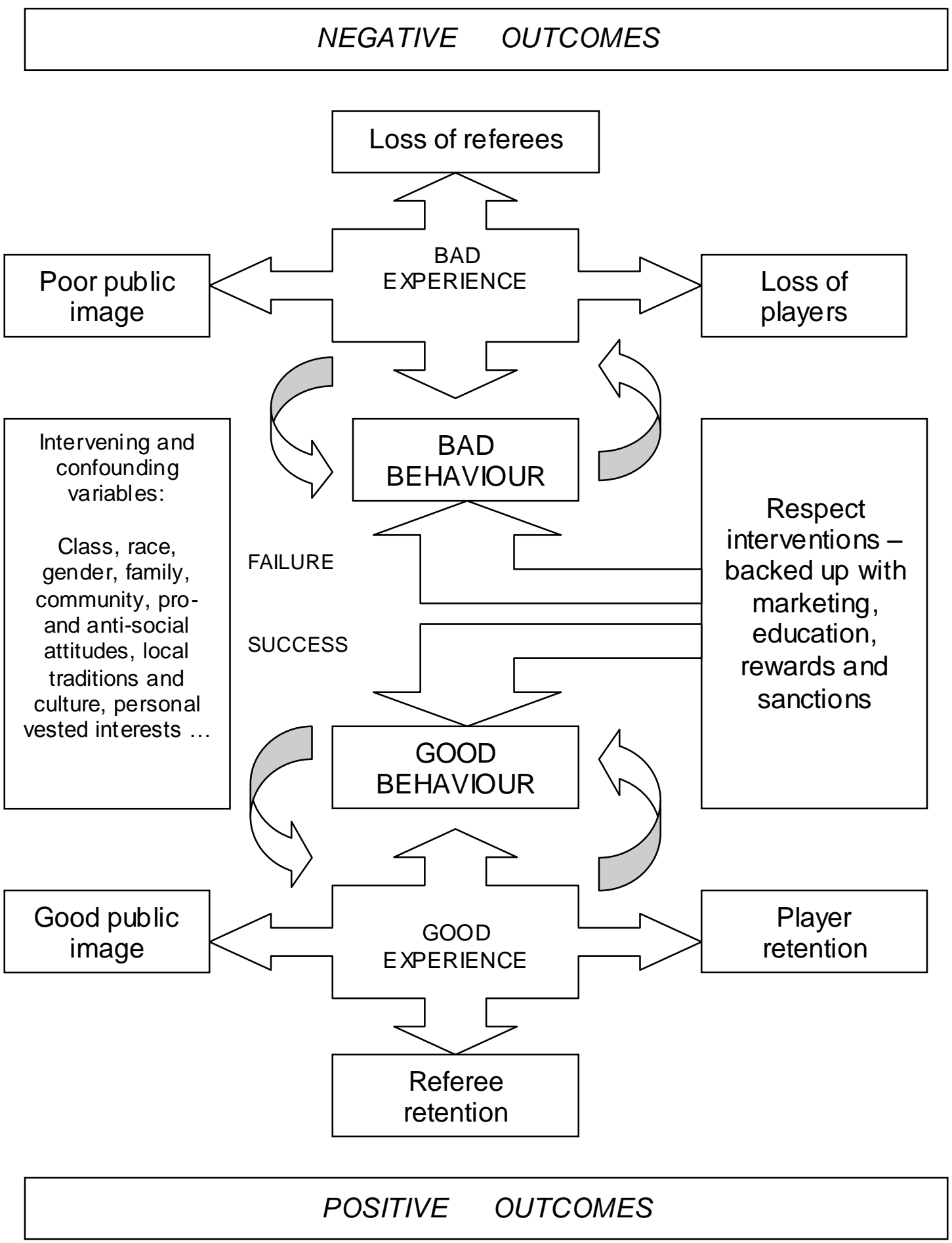


Figure 2 Overall enjoyment scores

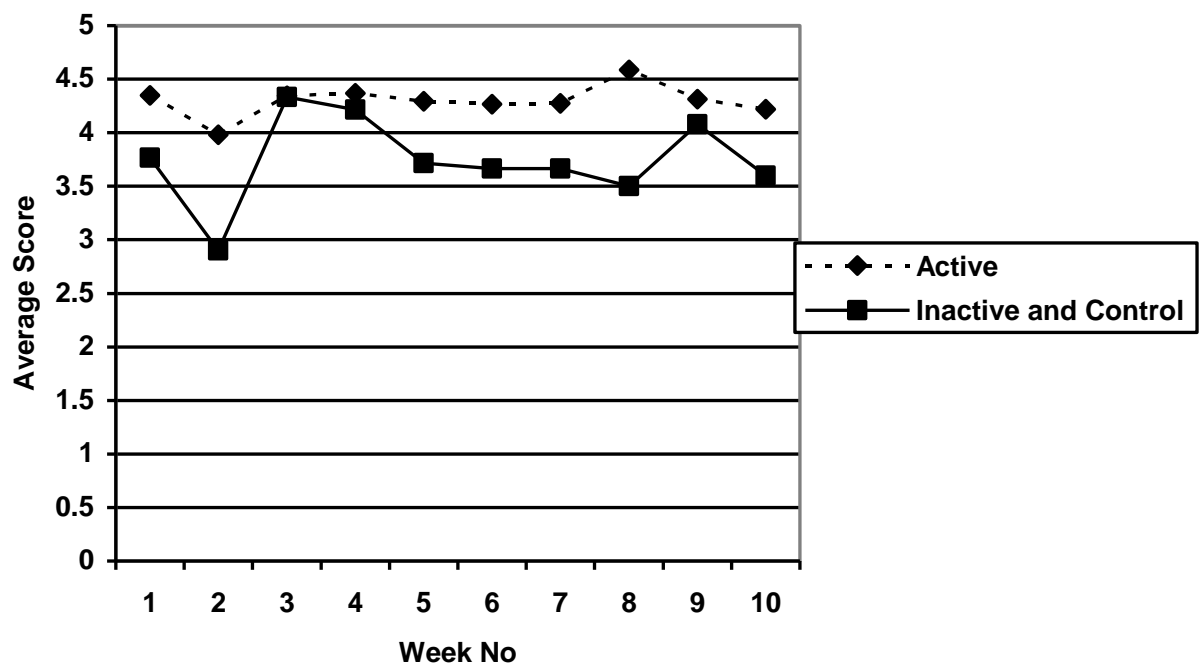

Figure 3 Overall behaviour scores

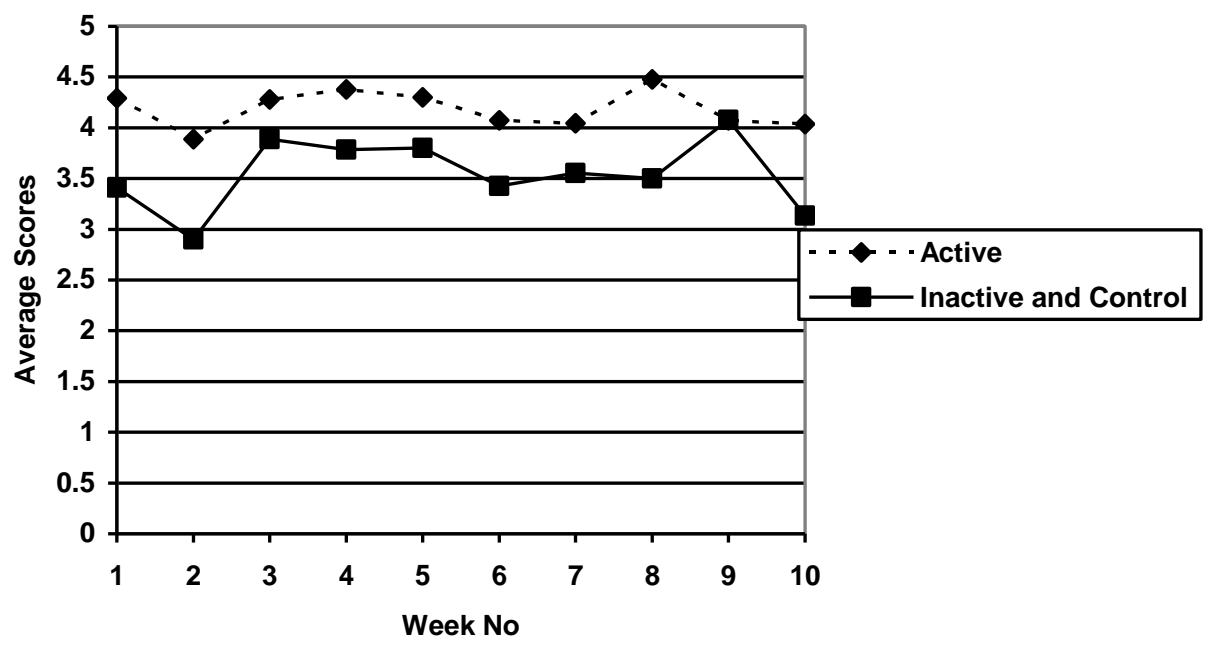


Figure 4 Experimental group views of interventions

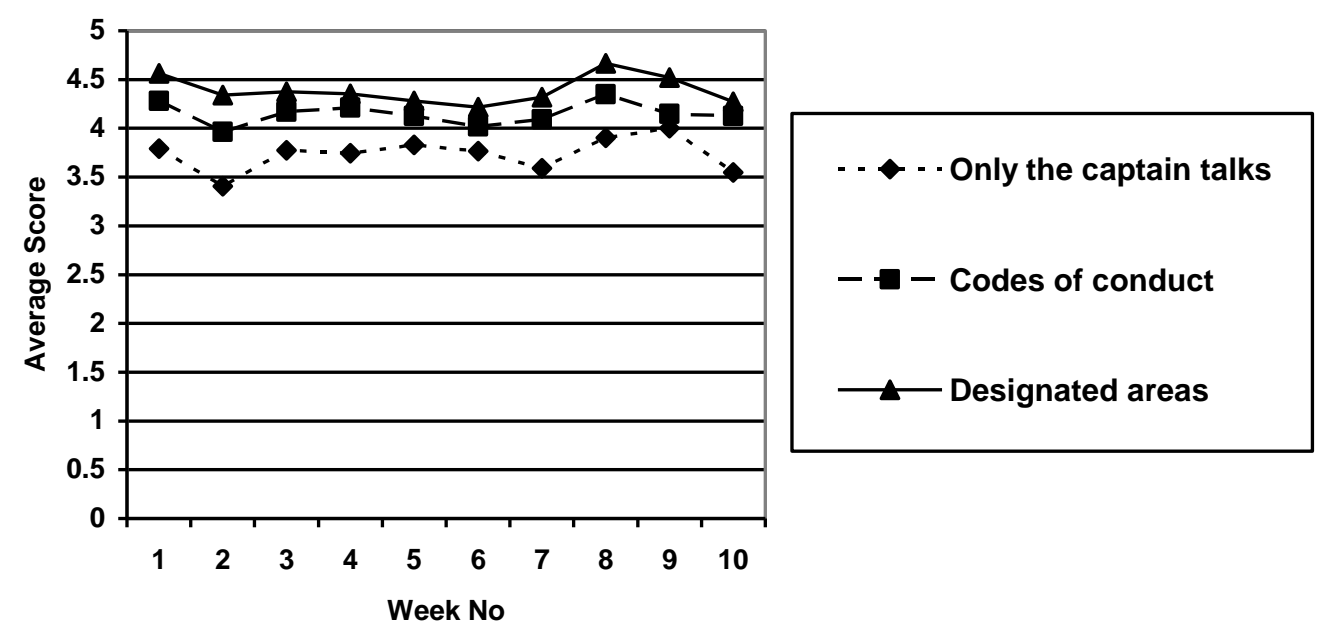


Figure 5 Designated areas by role

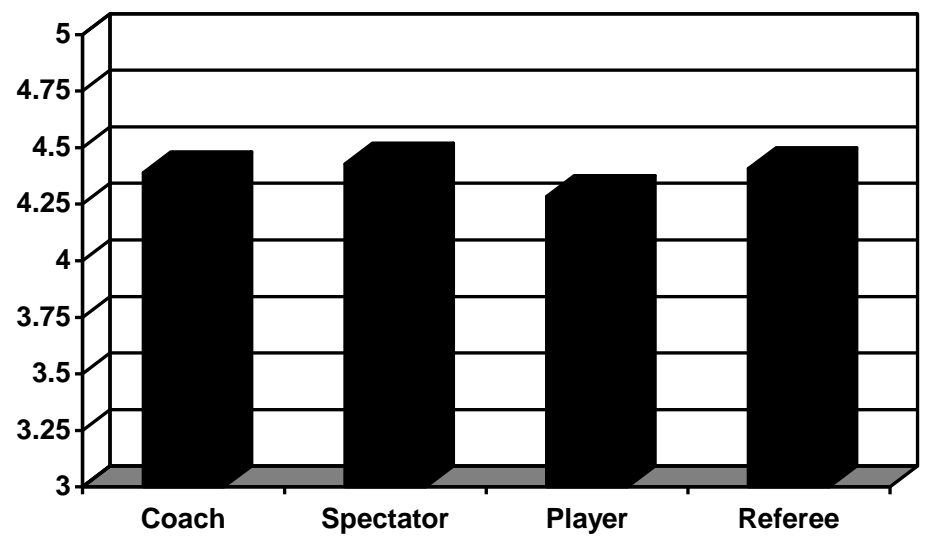

Figure 6 Designated areas by age group

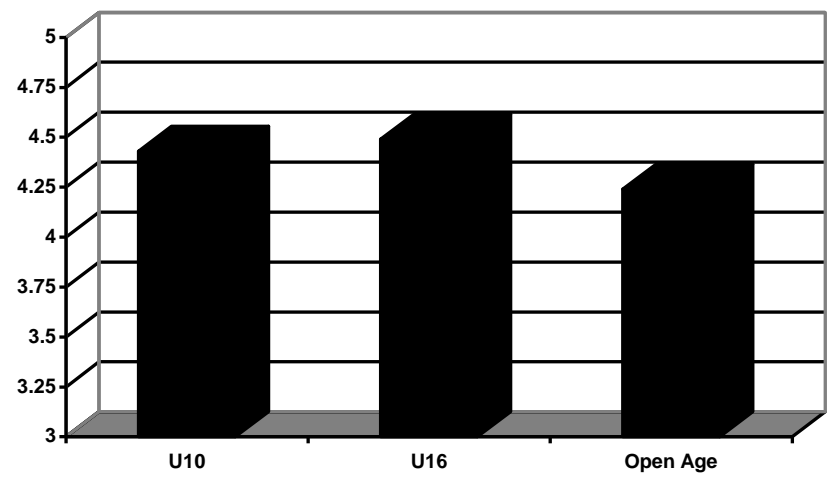


Figure 7 Codes of conduct by role

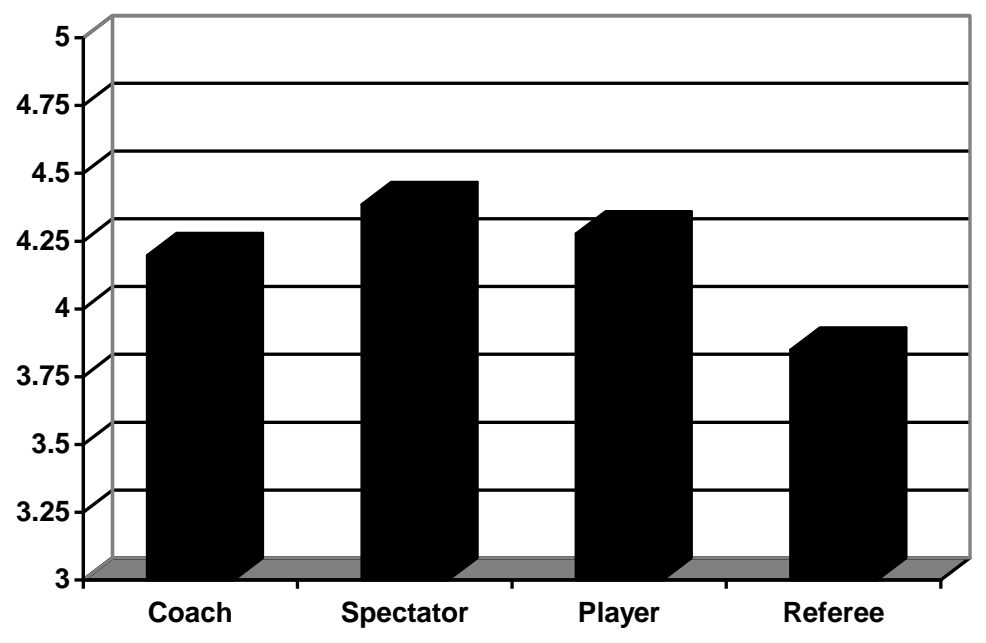


Figure 8 Only the captains speak by role

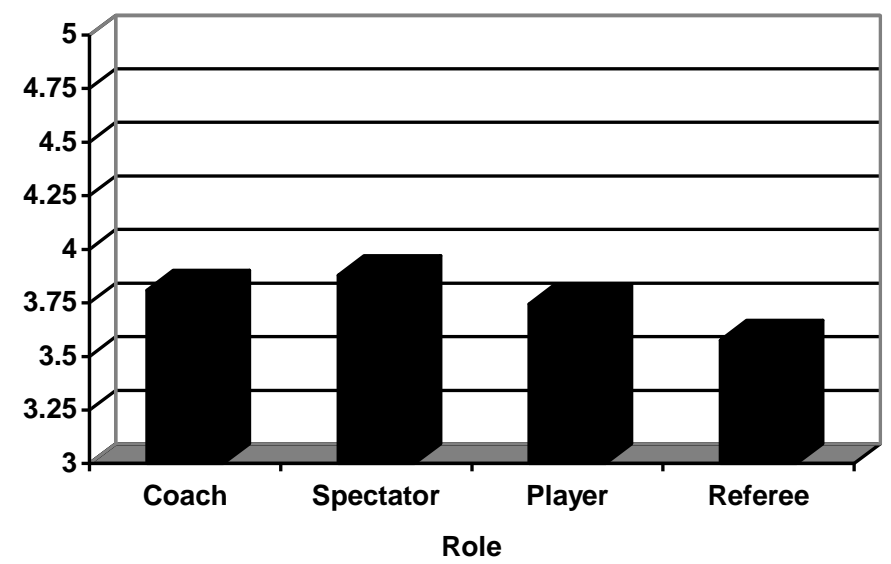

Figure 9 Only the captain speaks, by age group

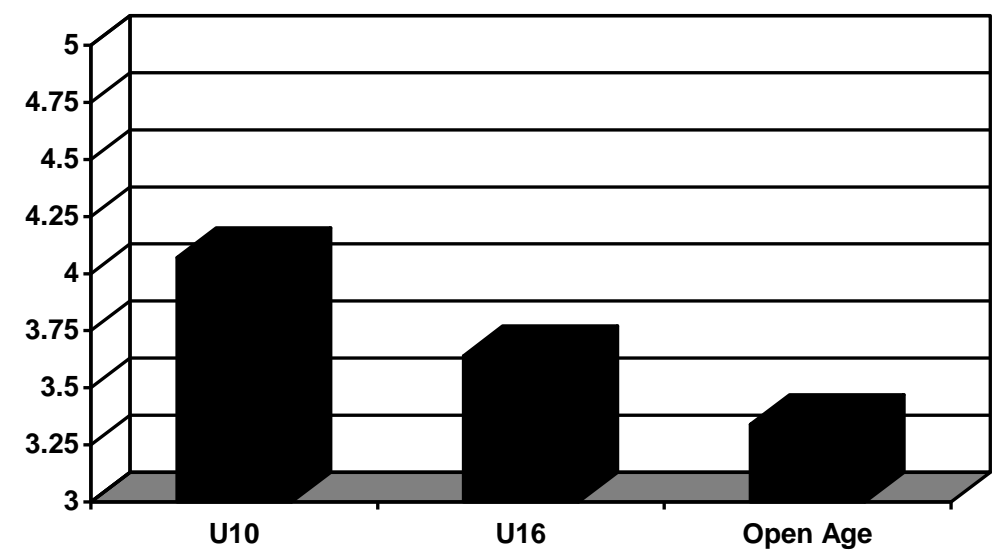

